\title{
Investigating Classroom Interaction: Teacher and Learner Participation
}

\author{
Babikir Eltigani Siddig ${ }^{1} \&$ Yahya Ashour AlKhoudary ${ }^{1}$ \\ ${ }^{1}$ English Department , Al Buraimi University College, Sultanate of Oman \\ Correspondence: Babikir Eltigani Siddig, English Department, Al Buraimi University College, Sultanate of \\ Oman.
}

Received: October 8, 2018 Accepted: November 13, 2018 Online Published: November 16, 2018

doi: 10.5539/elt.v11n12p86 URL: https://doi.org/10.5539/elt.v11n12p86

\begin{abstract}
This study on teacher and learner interaction was carried out with the sole purpose of understanding the collaborative behavior and the impact of different individuals on classroom environment. The study further analyzed the suitable methods of improving and maintaining a good learning environment. The administration of the questionnaire is the best method apart from observation and interviews among other approaches to effectively analyze learning in the classroom. The research further observed the impact of communication, behavior, and attitude in the learning environment (Fraser, 2012). This study also observed how the teacher can influence the student's career directly or indirectly based on the mode of conducting their teaching practices in a classroom environment. Also, the model of classroom interaction formulated is comprehensive of interrelated factors such as effects of a foreign language on learning, outer contexts surrounding classroom, learning materials, and learning objectives.
\end{abstract}

Keywords: interactive learning, behavior, attitude, communication, classroom environment

\section{Introduction}

Classroom health environment palys a vital role to assess the collected data that contribute in improving students' learning output (Fraser, 2012). Comprehensive studies have been carried out by a number of scholars have given a substantial contribution to leaning English as well as promoting classroom interaction. Besides, various publications on student response, the language of the educator/teacher are widely covered by various articles. However, classroom interaction between teacher and student lack fixing to have interactive healthy learning environment. This study illustrates the significance and the scope of the classroom environment as a vital issue to the concerend learners.

This study compares the old skills and the new learning features in the classroom in order to improve knowledge transfer and better student-teacher relationship (Cao, 2011). It attempts to develop a new hypothesis on the meaningful behaviors experienced and related behavior disparities between student and teacher in the classroom. Taking account of various personalities with different social, economic and religious experience are factors that are encountered in the classroom. Therefore, it requires well-trained teachers to involve all students in order to achieve competent participation in the classroom.

\subsection{Objectives of the Study}

- To find out the role of the teacher in molding student career.

- To estimate the attitude of the learner and the teacher towards learning environment.

- To find out the impact of behavior on teacher-learner relationship.

\subsection{Importance of the Problem}

Student-teacher interaction is essential since it plays a vital role in developing a positive trajectory of student academic progress and also a social improvement. The developed relationship makes the classroom a safe place and comfortable. Therefore, this study helps in curbing the existing limiting factors in the learning environment. Furthermore, the classroom environment is essential since it provides the student with the gut to share their 
emotional, social intelligence and self-esteem. As a result, such healthy class environment encourages students to work independently and engage in learning process.

\subsection{Literature Review}

This study was carried out over a long period of time with the use of evidence on the strong relationship between teacher and student which are the essential component in academic development. Fraser (2012) argued that nature and the quality of the teacher has a great significant impact on learning. This literature observes the steps carried out by the scholars to standard classroom environment to achieve effective learning.

The best teachers are not only well-oiled machines but further, they are passionate beings, emotional, creative and ready to face challenges. The study, therefore, focused on the importance of having a supportive teacher who can develop good relations with a student and help them better their learning skills (Buzzelli, \& Johnston, 2014).

The behavior has a greater replica of attitude and compassion to better or worsen the situation. When students perceive that their teacher is trustworthy and supportive in creating connections, they trust the teacher attitude towards presenting teaching materials easily (Cao, 2011). A good classroom environment can be designed to be excellent by having good social-emotional climate a teacher engage student hence making them see themselves as confident, worthy and capable in a classroom environment.

\section{Method}

In this study, a questionnaire on teacher-student interaction attitude scales was used. Although, the study also observed the participants based on the decision to breach the gap between the learners and teachers in college learning. The instruments were presented in a simple form that can be responded by both students and the teacher easily. The instruments for learning mentioned above contribute to the understanding of the socio-psychological environment of the classroom. Previous studies employed multiple methods of obtaining data opposed to this study it uses view instruments making it most economical and least time is required for research to elapse (Park et al., 2011). The table below shows the anticipated outlook of the result from student ranging from $20-40$ in a classroom.

Table 1. Scale description with examples of anticipated outcome of interaction questionnaire

\begin{tabular}{|c|c|c|}
\hline Scale & Description & Item \\
\hline $\begin{array}{l}\text { Student } \\
\text { Cohesiveness }\end{array}$ & $\begin{array}{l}\text { The extent to which students are supportive and } \\
\text { friendly to each other. }\end{array}$ & $\begin{array}{l}\text { I befriend with other students and I } \\
\text { appreciate their feedback. }\end{array}$ \\
\hline $\begin{array}{l}\text { Teachers } \\
\text { Support }\end{array}$ & $\begin{array}{l}\text { The extent to which the teacher befriend and help } \\
\text { student nature their talents. }\end{array}$ & $\begin{array}{l}\text { The teacher contributes to my personal } \\
\text { interests. }\end{array}$ \\
\hline Involvement & $\begin{array}{l}\text { The extent to which students interest in other } \\
\text { students affairs and participate in class work. }\end{array}$ & I share my ideas at class \\
\hline Investigation & $\begin{array}{l}\text { The extentwhich student and teachers push } \\
\text { research and assess the viability of the new idea. }\end{array}$ & $\begin{array}{l}\text { We intensify on testing new idea including } \\
\text { seeking idea from our teachers at the } \\
\text { classroom. }\end{array}$ \\
\hline Task Orientation & $\begin{array}{l}\text { The extent to which is essential to complete } \\
\text { planned activities and stick on the subject matter. }\end{array}$ & $\begin{array}{l}\text { It is important to get a certain amount of } \\
\text { work done and not drifting out of subject } \\
\text { matter. }\end{array}$ \\
\hline Cooperation & $\begin{array}{l}\text { Extend to which student cooperate at the } \\
\text { classroom. }\end{array}$ & $\begin{array}{l}\text { I cooperate with other student and I get } \\
\text { assistance regarding assignment when } \\
\text { stack. }\end{array}$ \\
\hline Equity & $\begin{array}{l}\text { Extend to which teacher share information } \\
\text { equally, questions and opportunities to in } \\
\text { cooperating discussion. }\end{array}$ & $\begin{array}{l}\text { The teacher attends to my question equally } \\
\text { providing time to discuss on it further. }\end{array}$ \\
\hline
\end{tabular}

The data was collected from all the different classes in the college, the teaching staff and even non-teaching personnel were interviewed. The selected individuals were picked randomly, therefore, blending on the data to be obtained.

The students were asked to provide their views based on five-points such as Almost never, Rarely, Sometimes, 
often and Almost Always. The response may vary from student to another based on how everyone perceives classroom occurrence. The total score for particular scale depends on the number of responses, unmarked question or answered wrongly will be considered to 3 marks. The more the scale suggests that the classroom practice occurs in that regard.

Interaction is the mutual process where there is no dominant party leading another, instead, both are taking part in contributing to the issue being handled. This study shows that; it is not proven scientifically that voluntary investigation can yield the best result in a particular field of study (Fraser, 2012). Although, there has been a shift in study focus from the kind of language used to the kind of interaction between native speakers of the language and to the second language acquirers. To get students achieve higher degree of communicative competence, there is a need to adapt interactive method in classrooms. The person-to-person encounter is believed to be inherited from the notation of classroom pedagogy. There are five aspects of interaction that are applicable inside and outside of the classroom environment: tone, code, management of turn topic and task.

College-level of education is prerequisite for students to interact in an effective learning to reach satisfaction at colleges and universities. Interactive class opposed to the lecture that involves all people in classroom activities. The questionnaire is an explicit tool to study in such an effective environment to validate on the prevailing condition. The comments obtained from the study rewards for the successful understanding of the classroom environment. The findings of this research may suggest an inter-personal relationship of the teacher, implying that this study obtains data to analyze scales required in the learning environment (Fraser, 2012).

The study has presented the modified skills that are essential for assessing teacher-student interaction at college-level (Fr Sakiz et al., 2012). Feedback received from students and comment made by their teachers cumulatively result to the anticipated outcome. Table 1 shows the scales that are meant to analyze the behavior and attitude of students. The reliability and validity of data must be achieved to avoid jeopardizing good relations of teacher-student that existed before the study was done. The questionnaire is, therefore, comprehensive of behavior and the psychological related questions that enable the researcher to find out unjust respondent from the various student involved.

To accomplish the purpose of this research, subsequent questions were raised:

1) What is the frequency occurrence of the different types of learning in the college?

2) What is the effect of teacher-learner interaction on learning process?

3) How effective the study in engaging teacher-learner cognitively?

\section{Results}

The findings of this study are subject to three dimensions: validation of questionnaire and attitude to scale, understanding student behavior and motivation base on the course they pursue an association of student's response and teacher-student interaction.

Table 2. Internal consistency (alpha reliability) for questionnaire scales for students and teachers in three countries

\begin{tabular}{lllcc}
\hline Scale & Students/ & Alpha Reliability & & \\
& Teacher & The USA & Australia & Netherlands \\
\hline DC leadership & Student & 0.83 & 0.80 & 0.83 \\
& Teacher & 0.81 & 0.75 & \\
CD Helping/friendly & Student & 0.90 & 0.88 & 0.82 \\
& Teacher & 0.78 & 0.74 & \\
CS Understanding & Student & 0.90 & 0.88 & 0.78 \\
\multirow{3}{*}{ SC student responsibility/freedom } & Teacher & 0.83 & 0.76 & \\
& Student & 0.74 & 0.76 & 0.66 \\
& Teacher & 0.72 & 0.82 & \\
\hline
\end{tabular}




\begin{tabular}{lllll}
\hline \multirow{3}{*}{ OS Dissatisfied } & Teacher & 0.83 & 0.79 & \\
& Student & 0.86 & 0.83 & \\
OD Admonishing & Teacher & 0.83 & 0.75 & 0.71 \\
\multirow{3}{*}{ DO Strict } & Student & 0.81 & 0.84 & \\
& Teacher & 0.71 & 0.81 & 0.63 \\
Sample size & Student & 0.78 & 0.80 & \\
& Teacher & 0.61 & 0.84 & 649 \\
\hline
\end{tabular}

Data collected were obtained from the scale inter-correlation from Table 2. Stated earlier in the text, there existed eight behavior scales used to study in classroom environment. Some of the models exhibits overlapping results, for example, helpful/friendly and understanding. Opposed to helpful/friendly and dissatisfied which must have a highest negative correlation. This study has great ability to differentiate between different teachers, since different instructor exhibit different personal behavior apparently, the questionnaire was sensitive to enable distinguish specific responses provided by the different classes.

\section{Discussion}

This study focused on perceived classroom environment and interaction between teacher and student (Fraser, 2012). Career development is essential during study time of the student and therefore, there was the agency to have a detailed understanding of strengths and weakness in the classroom. The study investigated behavior, intuition, attitude and teacher's role in molding students. The methodologies applied during the entire study employed revised scientific research. It was observed that this research is economical, effective and efficient compared to observation and interviews which required a lot of time and resources.

Analysis of data obtained using questionnaire from student and the teaching staff in college resulted in accepting eight-scale factors. The scales satisfied the study assumption models that there existed more correlations to those close than the difference to those scales exhibited. The research also observed relatively high internal consistency and expressed ability of the questionnaire to differentiate responses of students from various classes (Fraser, 2012).

In terms of student's general perceptions, teachers were perceived to be dominant and were most cooperative. The role of the teacher is leadership and mentorship. Additionally, those teachers who involved the student in recreational activities were significantly linked with certain behavior and attitude. The effect of proximity attitude varies from student to student, however, research can be compared to other studies and it support that interaction is a large field that comprehends various believes and cultures to influence the ultimate performance in a classroom.

The teacher's perception of his own behavior does not match with the perception made by the student. He perceived higher score at some scales like friendly and leadership sectors than the students thought. The differences of the scales admonishing and dissatisfied, showed that the student has more score than the teacher. Therefore, their actual behavior and the perception do not correspond. The views of ideal and actual teachers are close that imply that most of the teachers have similar features compared to the student who exhibited a varied response to the classroom environment. Therefore, the teacher has to provide a greater degree of freedom to the student. The student will prefer such a conditionsince there is a need to develop pedagogic confidence in a classroom talk which gives the students a chance to talk and be active in creating their own understanding.

\section{Conclusion}

The questionnaire investigating teacher and learner in the classroom environment has been establishing to be a valid, economical and reliable tool to provide the college with relevant information about their classroom environment (Aldridge \& Ala'I, 2013). The questionnaire is valuable particular that it enables them to compare what they had and the perception with students. Nevertheless, the questionnaire has the capacity to provide the teacher with information to compare between ideal teacher and actual teacher. This item provides teachers with a discussion on a single aspect of their teaching behavior. 


\section{Recommendations}

In the light of the findings of this study, there are certain factors when adapted in an effective learning environment may help alter attitude and performance in the classroom. The study has not covered gender inequity and students with disabilities (Wilkinson \& Marrett, 2013). To widen facilitation in a classroom, teachers are entitled responsibility to control and incooperate those students that are physically challenged. The government in the other hand need to provide basic training to all teachers during training levels, (diploma or degree level) to ensure that teachers are equipped with skills and knowledge to facilitate to serve all kinds of students when they are posted to various colleges and even other education levels.

It is observed from the study that, there are students who do not have good English backgrounds; therefore, such students require acquainted approach and methodology to ensure that they are encouraged to further career effectively. Dealing with different types of conversations, it is necessary that time is allocated to such students to ensure they get the best out of their study environment.

\section{References}

Aldridge, J., \& Ala'I, K. (2013). Assessing students' views of school climate: Developing and validating the What's Happening In This School?(WHITS) questionnaire. Improving schools, 16(1), 47-66. https://doi.org $/ 10.1177 / 1365480212473680$

Aldridge, J. M., \& Fraser, B. J. (2016). Teachers' views of their school climate and its relationship with teacher self-efficacy and job satisfaction. Learning Environments Research, 19(2), 291-307. https://doi.org/10.1 007/s10984-015-9198-x

Buzzelli, C., \& Johnston, B. (2014). The moral dimensions of teaching: Language, power, and culture in classroom interaction. Routledge. https://doi.org/10.4324/9781315054674

Cao, Y. (2011). Investigating situational willingness to communicate within second language classrooms from an ecological perspective. System, 39(4), 468-479. https://doi.org/10.1016/j.system.2011.10.016

Fraser, B. J. (2012). Classroom learning environments: Retrospect, context and prospect. In the Second international handbook of science education (pp. 1191-1239). Springer, Dordrecht. https://doi.org/10.100 7/978-1-4020-9041-7_79

FrSakiz, G., Pape, S. J., \& Hoy, A. W. (2012). Does perceived teacher affective support matter for middle school students in mathematics classrooms? Journal of school Psychology, 50(2), 235-255.

Park, J. M., Choi, M. G., Cho, Y. K., Lee, I. S., Kim, J. I., Kim, S. W., \& Chung, I. S. (2011). Functional gastrointestinal disorders diagnosed by Rome III questionnaire in Korea. Journal of neurogastroenterology and motility, 17(3), 279. https://doi.org/10.5056/jnm.2013.19.3.279

Walsh, S. (2011). Exploring classroom discourse: Language in action. Routledge. https://doi.org/10.4324/9 780203827826

Wilkinson, L. C., \& Marrett, C. B. (Eds.). (2013). Gender influences in classroom interaction. Academic Press.

Zarrinabadi, N. (2014). Communicating in a second language: Investigating the effect of teacher on learners' willingness to communicate. System, 42, 288-295. https://doi.org/10.1016/j.system.2013.12.014 


\section{Appendix A}

Investigating Classroom Interaction Questionnaire

Student questionnaire

To the institution coordinator: This questionnaire is conducted as part of research aiming to improve the learning environment at college. Personal information provided during the course study will be treated with confidentiality.

You are being advised to fill the following information and please tick where it is appropriate according to your perception.

\section{Part A: Participant's information}

1. District

2. Area

$\square$ Urban $\square$ Rural

3. Gender

$\square$ Male $\square$ Female

4. Year of admission

5. Current year of study

6. Your language of communication

7. English language proficiency

$\square$ Low $\square$ medium $\square$ satisfactory $\square$ standard

Part B: class interaction

a) Who conducts the talk in the class mostly?

$\square$ teacher $\square$ student $\square$ teacher and student

b) Which language does your teacher use in the classroom

$\square$ English $\square$ Other

c) If other specify which language

d) How often does your teacher let you share ideas in the classroom?

e) $\square$ Always $\square$ often $\square$ sometimes $\square$ seldom $\square$ never

f) Does regular interaction in the classroomhelp you to improve your learning? Why, please?

g) If you do not interact, it is because:

a) You are not talkative

b) The topic is not interesting

c) The teacher fails to apply the teaching techniques

d) The teacher does not motivate

e) You fear to make mistakes

h) Do have any suggestions? 


\section{Appendix B}

Investigating Classroom Interaction

Interview questions for the teacher

Part A: (participant information)
a) District
b) Area $\square$ urban $\square$ semi-urban $\square$ rural
c) Gender $\square$ Male $\square$ Female
d) Educational qualification MA
BA
e) Teaching experience $\square 0-5$ Years
f) Participated in any study of classroom interaction $\square$ Yes
$11-15$ Years
16-20 Years
$\square 21+$ Years

\section{Part B Interaction}

1) Which language do you use when teaching your students? Reason?

2) What are some of the interactive activities do you involve your students?

3) How do these practices improve learning in your classroom?

4) Do you prefer if students work in pairs/groups? Why so or why not?

5) What are the common aspect the interfere with effective classroom interaction?

6) How do you overcome those factors?

7) Briefly give your suggestion?

\section{Copyrights}

Copyright for this article is retained by the author(s), with first publication rights granted to the journal.

This is an open-access article distributed under the terms and conditions of the Creative Commons Attribution license (http://creativecommons.org/licenses/by/4.0/). 